\title{
Incidental Diagnosis of Healed Aortic Abscess Cavity
} Shilpa Shree $^{1}$, Vijayanand Palanisamy ${ }^{1}$, Kumar Chidambaram ${ }^{2}$, Vasanthi Vajjiram ${ }^{1}$, Pradeep Ramkoomar

1. Department of Cardiothoracic Surgery, The Madras Medical Mission Hospital, Chennai, IND 2. Department of Cardiac Anesthesia, The Madras Medical Mission Hospital, Chennai, IND

Corresponding author: Shilpa Shree, ss288181832@gmail.com

\begin{abstract}
In infective endocarditis, the perivalvular abscess is a known complication with an incidence of more than $22 \%-29 \%$, but the primary presentation of a healed aortic abscess without any clinical features of infective endocarditis is very rare. These sorts of cases are scarcely documented throughout literature. We present a successful surgical closure of healed perivalvular abscess cavity with aortic valve replacement and mitral valve repair.
\end{abstract}

Categories: Anesthesiology, Cardiac/Thoracic/Vascular Surgery, Cardiology

Keywords: abscess, cavity, infective endocarditis, aortic, echocardiography, valve, commissure, mitral leaflet

\section{Introduction}

A perivalvular abscess is a known complication of infective endocarditis (IE) with an incidence of around $22 \%-29 \%[1,2]$. Silent presentation of IE with a healed aortic abscess is very rare, with seldom documented cases throughout literature. Initially, two-dimensional echocardiography has shown to be useful in the diagnosis of abscess cavities. Due to the proximity of transesophageal echocardiography (TEE) probe to the aortic valve (AV) and higher signal-to-noise ratio, TEE was found to be a superior imaging modality in comparison to transthoracic echocardiography (TTE) [3,4]. IE usually presents with symptoms of fever, myalgia, flu-like symptoms, fatigue, chest pain, and signs like heart murmurs, anemia, or embolic events. Our patient presented with only complaints of breathlessness without any other clinical evidence of IE. Intraoperative TEE accidentally picked a rare healed aortic abscess cavity with a floor formed by the left atrium. We report a successfully performed direct closure of a healed perivalvular abscess cavity by including the cavity during AV implantation within the suture line itself.

\section{Case Presentation}

A 44-year-old gentleman presented with complaints of shortness of breath of 30 days' duration. On initial evaluation, his heart rate was 72 beats/min, blood pressure was $120 / 40 \mathrm{mmHg}$ and he was afebrile. We found an early diastolic murmur in the aortic area and a pansystolic murmur in the mitral area.

Review began 05/29/2021 Review ended 06/13/2021 Published 06/14/2021

(c) Copyright 2021

Shree et al. This is an open access article distributed under the terms of the Creative Commons Attribution License CC-BY 4.0., which permits unrestricted use, distribution, and reproduction in any medium, provided the original author and source are credited.
Electrocardiography (ECG) was suggestive of left ventricular (LV) hypertrophy and left atrial enlargement (Figure 1). 


\section{Cureus}

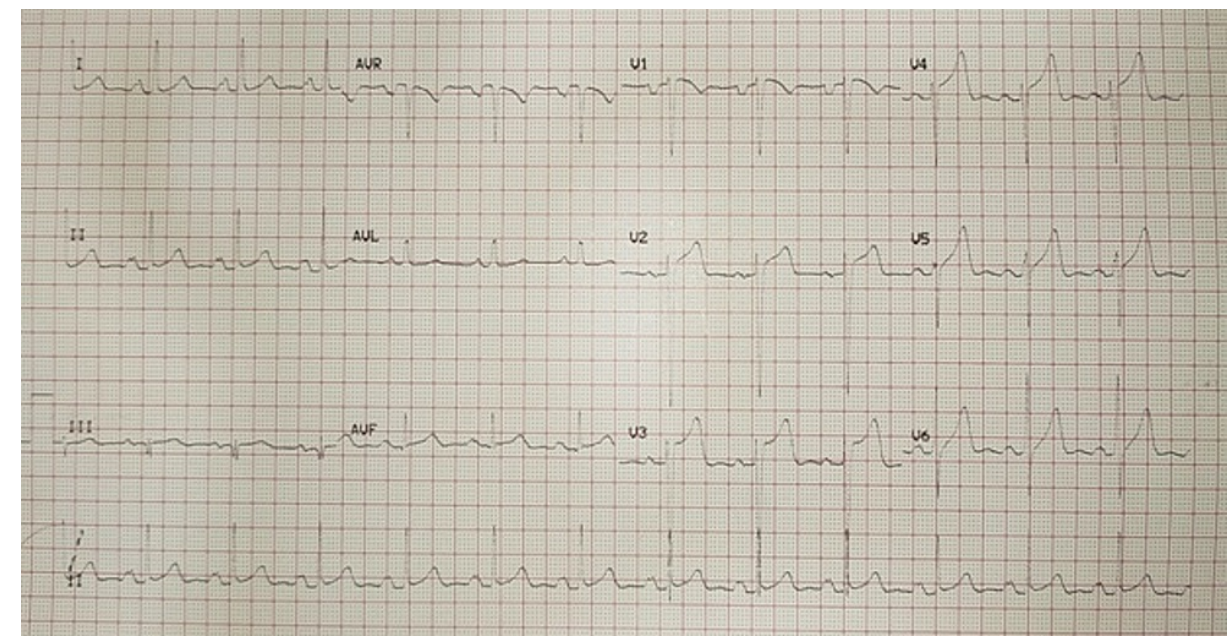

FIGURE 1: Electrocardiography showing left ventricular hypertrophy and left atrial enlargement

Chest roentgenogram showed LV enlargement (Figure 2).

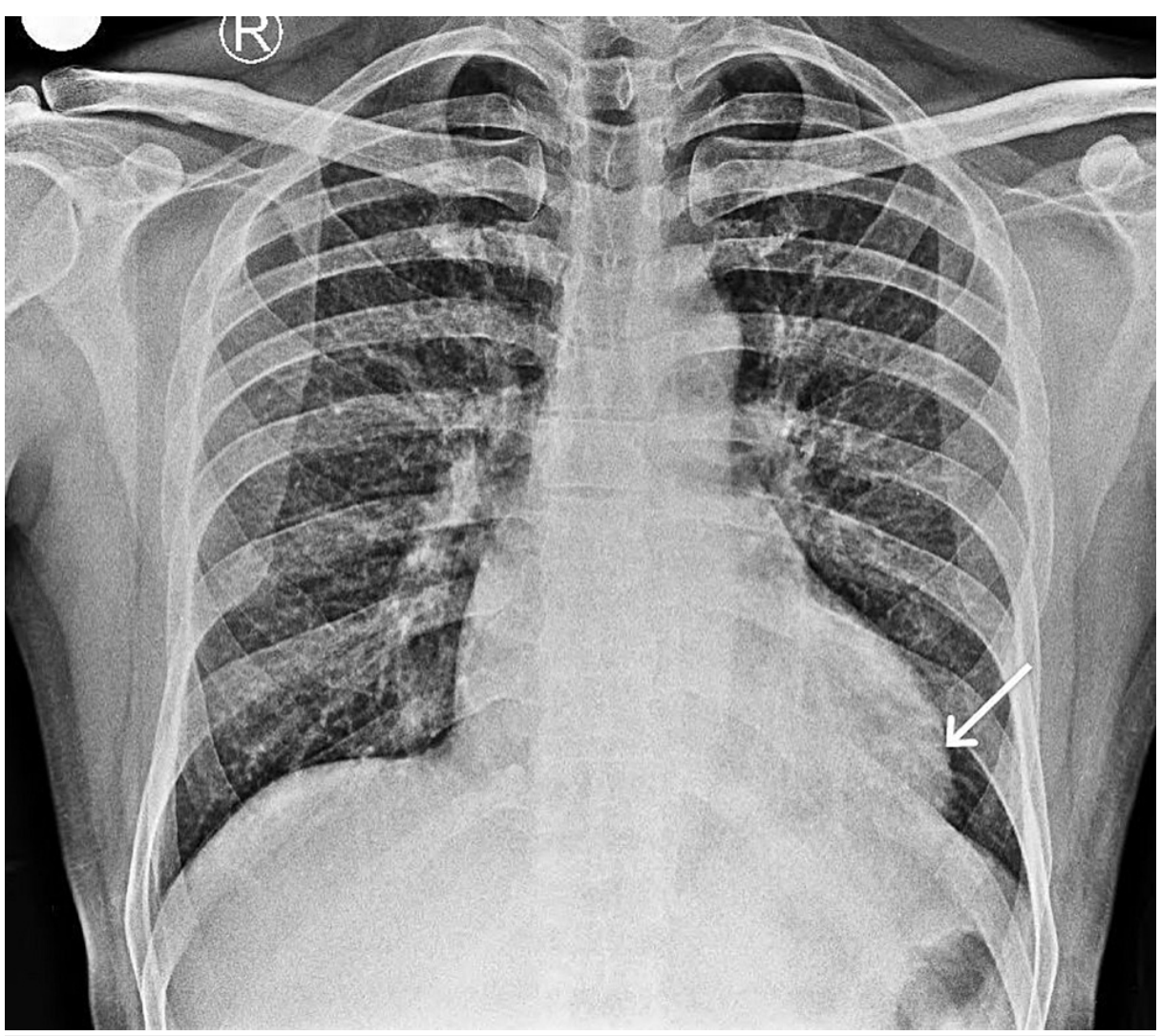

FIGURE 2: Chest roentgenogram

Arrow pointing left ventricular enlargement.

TTE (Figures 3A, 3B, 4A-4E, and 5A-5D) revealed severe eccentric aortic regurgitation (AR) (slope - 610 $\mathrm{cm} / \mathrm{s}^{2}$ ) with thickened and non-coapting AV, left coronary cusp (LCC) prolapsed, and moderate mitral regurgitation (MR) (jet area $-8.7 \mathrm{sqcm}$ ), moderate pulmonary hypertension, dilated LV - left ventricle internal diameter (LVID) diastolic - $69 \mathrm{~mm}$, and LVID (systolic) - $56 \mathrm{~mm}$, and moderate LV systolic dysfunction (ejection fraction - 38\%). Other valves were normal. The aortic annulus measured $2.2 \mathrm{~cm}$, ascending aorta $3.2 \mathrm{~cm}$, and sinotubular junction $3.1 \mathrm{~cm}$. He was scheduled to undergo AV replacement with the mitral repair. 


\section{Cureus}

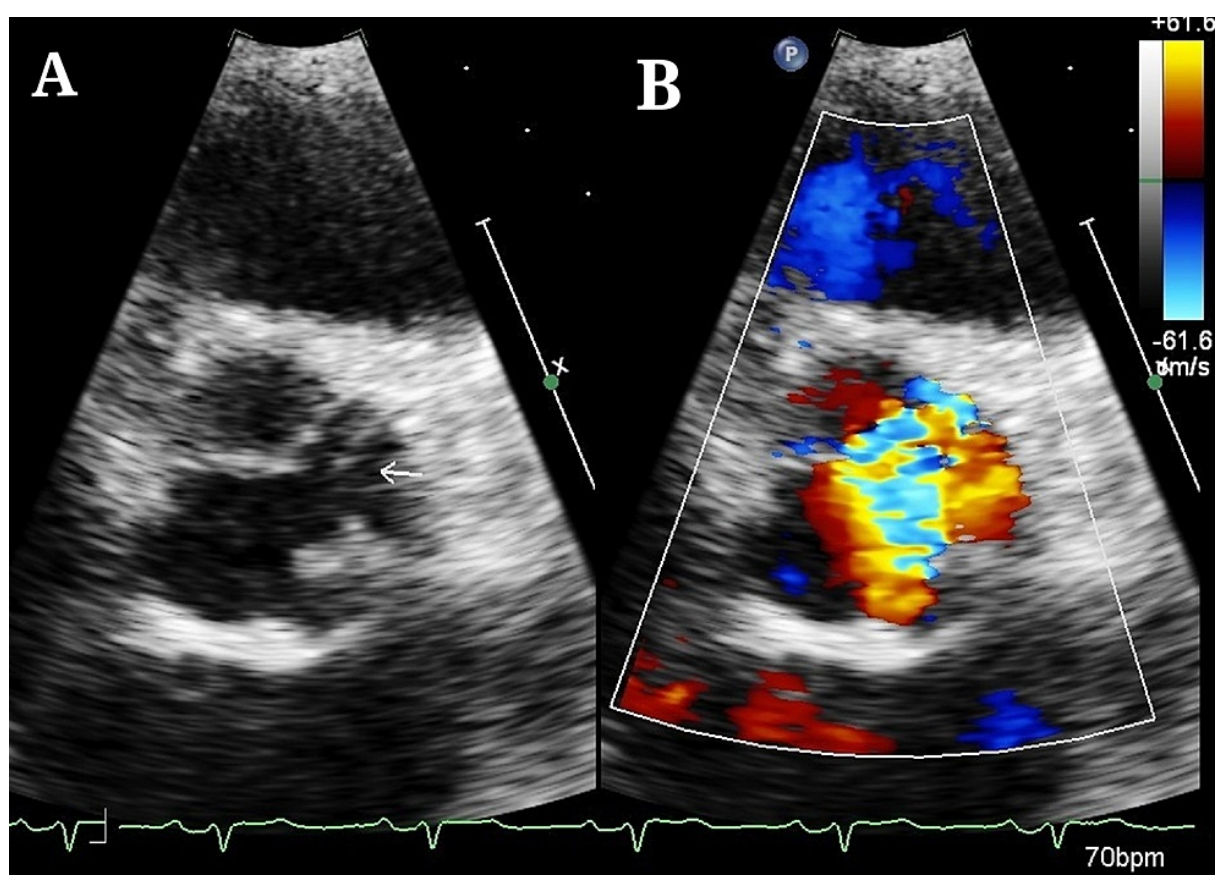

FIGURE 3: Transthoracic echocardiography - short-axis view

(A) Plain image with arrow showing left coronary cusp prolapse. (B) Color Doppler image showing regurgitation jet.

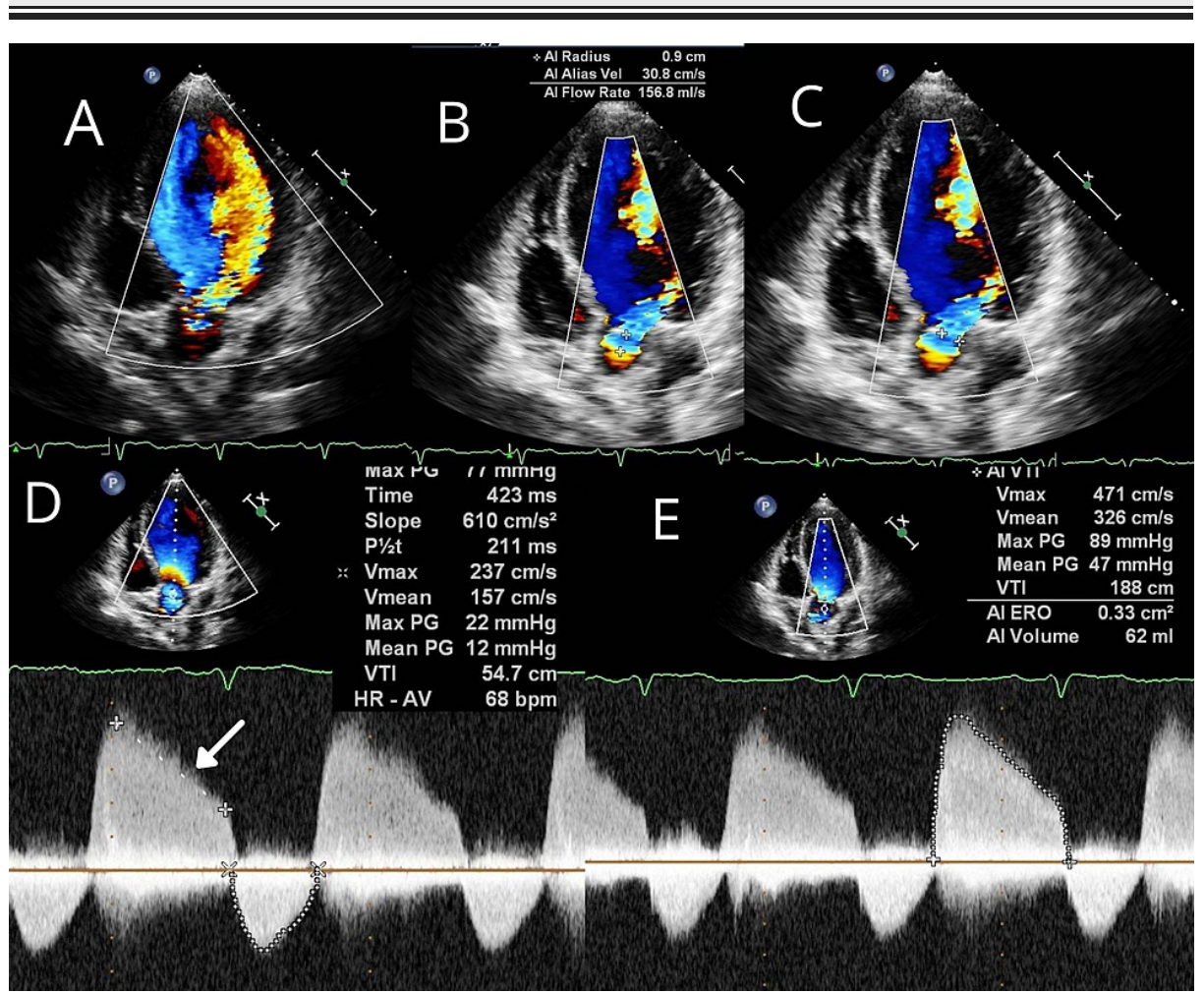

FIGURE 4: Transthoracic echocardiogram of aortic regurgitation

(A) Five-chamber view showing eccentric aortic regurgitation. (B) Five-chamber view showing proximal isovelocity surface area of $0.9 \mathrm{~cm}$. (C) Five-chamber view showing vena contracta $0.883 \mathrm{~cm}$. (D) Five-

chamber view with continuous-wave Doppler showing aortic deceleration slope $610 \mathrm{~cm} / \mathrm{s}^{2}$ and pressure half time $211 \mathrm{~ms}$. (E) Five-chamber view with continuous-wave Doppler showing effective regurgitant orifice area of $0.33 \mathrm{~cm}^{2}$. 


\section{Cureus}

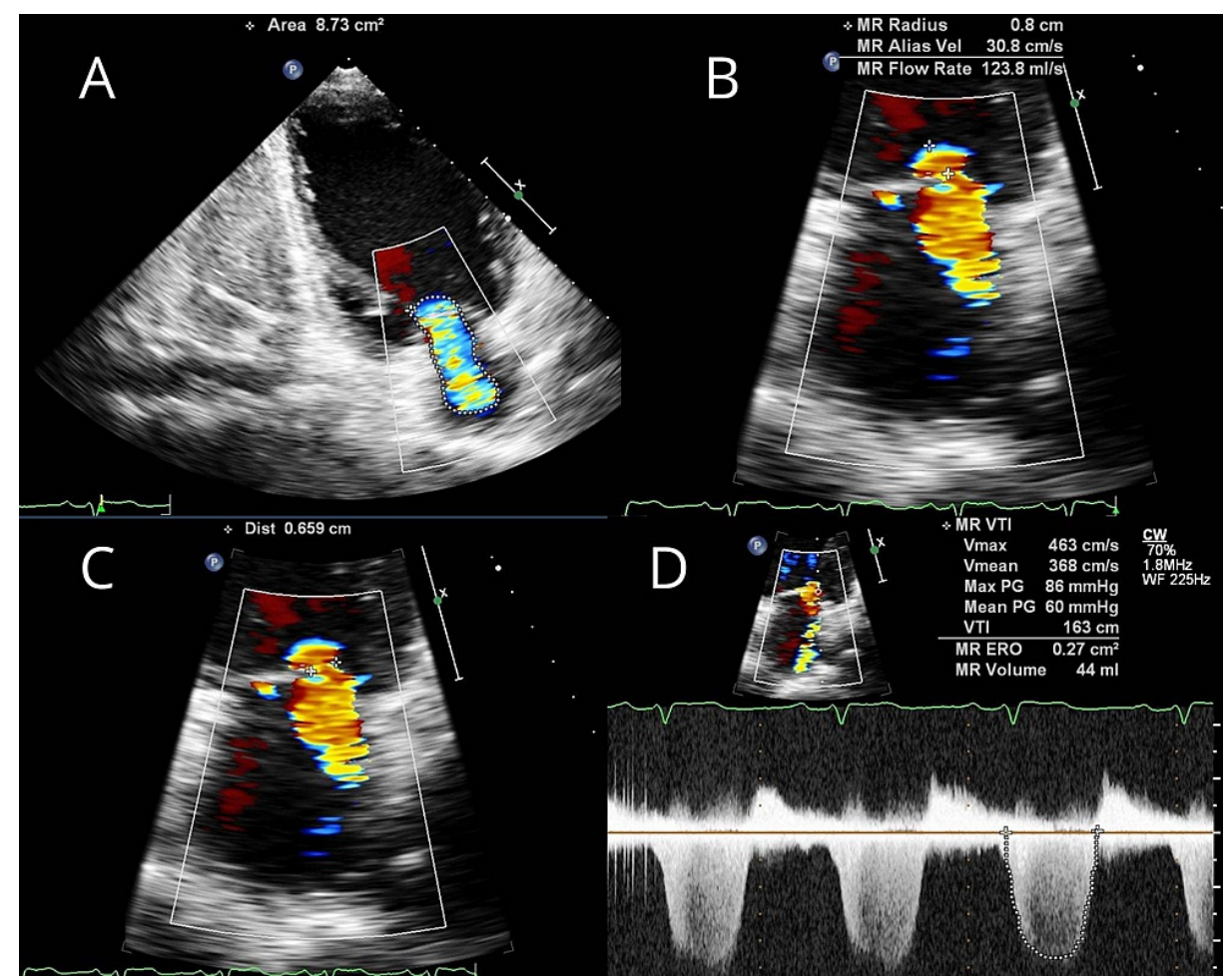

\section{FIGURE 5: Transthoracic echocardiogram of mitral regurgitation}

(A) Two-chamber view showing mitral regurgitation with jet area $8.73 \mathrm{~cm}^{2}$. (B) Four-chamber view showing proximal isovelocity surface area of $0.8 \mathrm{~cm}$. (C) Four-chamber view showing vena contracta of $0.659 \mathrm{~cm}$. (D) Four-chamber view with continuous-wave Doppler showing effective regurgitant orifice area of $0.27 \mathrm{~cm}^{2}$.

No history and clinical features suggestive of IE were found. Hematological and biochemical markers of endocarditis like total leucocyte count $\left(7,300\right.$ cells $\left./ \mathrm{mm}^{3}\right)$ and erythrocyte sedimentation rate $(8 \mathrm{~mm} / \mathrm{hr})$ were within the normal range.

Intraoperative TEE examination showed that the AV is trileaflet with severe AR and showed a cavity (Figures $6 \mathrm{~A}, 6 \mathrm{~B}$ ) near the non-coronary cusp - left coronary cusp (NCC-LCC) commissure extending to the base of anterior mitral leaflet and moderate MR. Three-dimensional (3D) TEE with the multi-beta acquisition with six ECG beats stitched together was done, which confirmed the same findings. 


\section{Cureus}

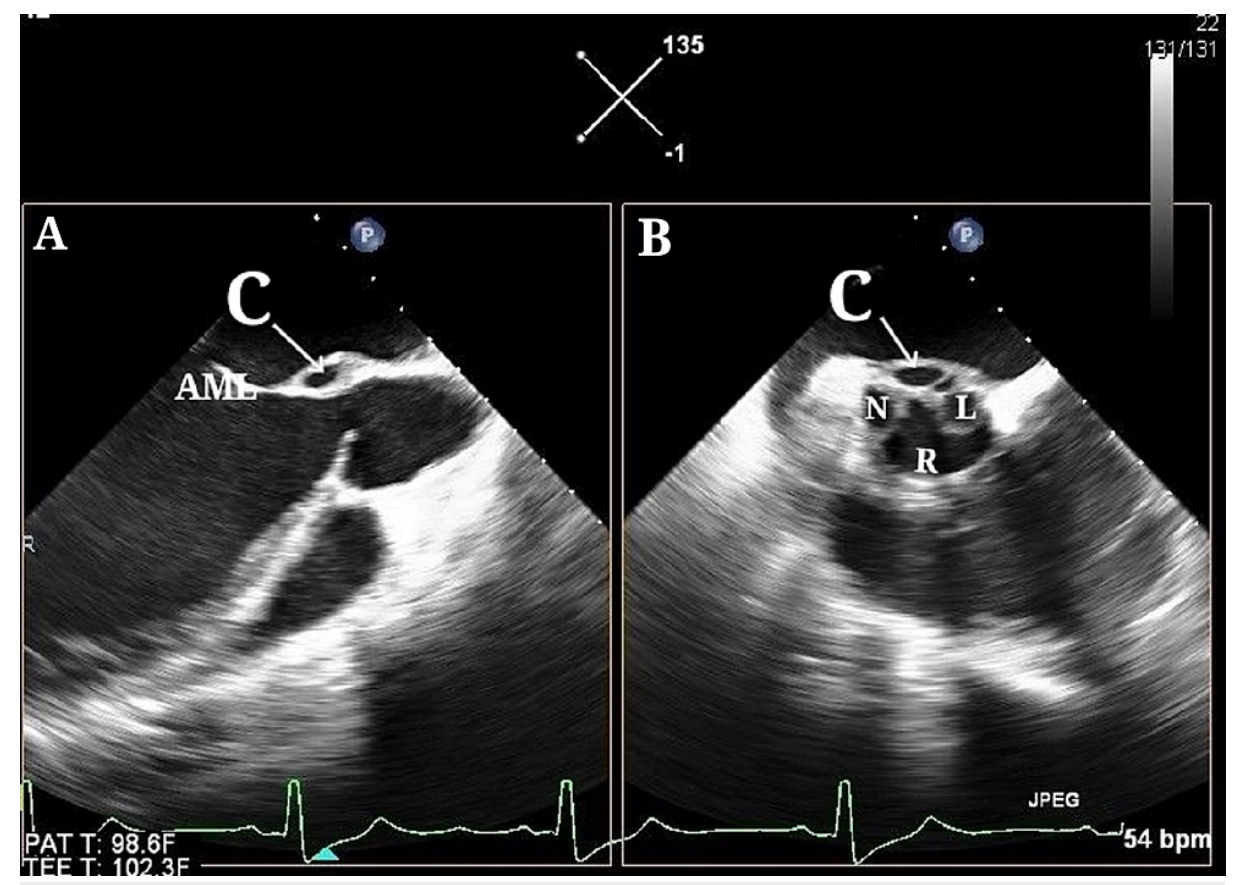

FIGURE 6: Transesophageal echocardiogram

(A) Orthogonal image 90-degree showing the cavity near AML. (B) X-plane or aortic valve short axis showing the cavity at NCC-LCC commissure.

C - cavity, $\mathrm{N}$ - noncoronary cusp, R - right coronary cusp, L - left coronary cusp, AML - anterior mitral leaflet.

Post sternotomy and pericardiotomy, we found a hugely dilated heart with moderate dilatation of the aorta. Cardiopulmonary bypass (CPB) was instituted using aorto-bicaval cannulation. Hypothermic Delnido cardioplegia was used for diastolic cardiac arrest. After aortotomy, we found a tricuspid AV with thickened and tethered non-coapting cusps. A healed aortic abscess cavity $1 * 1 * 0.5 \mathrm{~cm}$ was seen at the NCC sinus close to NCC- LCC commissure (Figure 7). 


\section{Cureus}

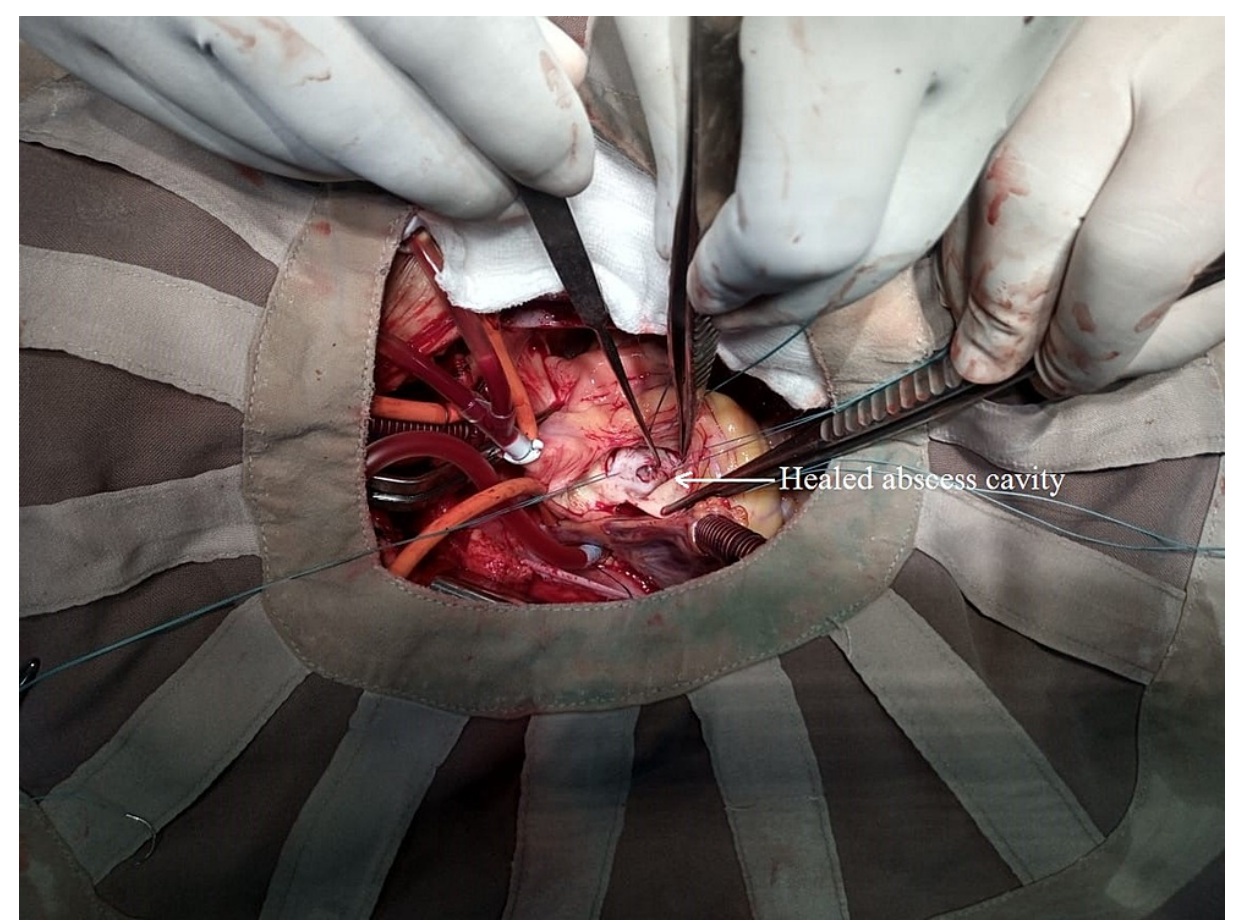

FIGURE 7: Intra-operative image showing the abscess cavity nearer to NCC-LCC commissure with left atrial musculature at its base

Left atrial wall musculature was seen at the base of the cavity. We excised the native AV. A 24-mm aortic mechanical valve was implanted in the aortic position with continuous suture technique. The healed abscess cavity was directly obliterated by including it in the suture line and plicated along with the sewing ring of the prosthetic valve (Figure 8 ). 


\section{Cureus}

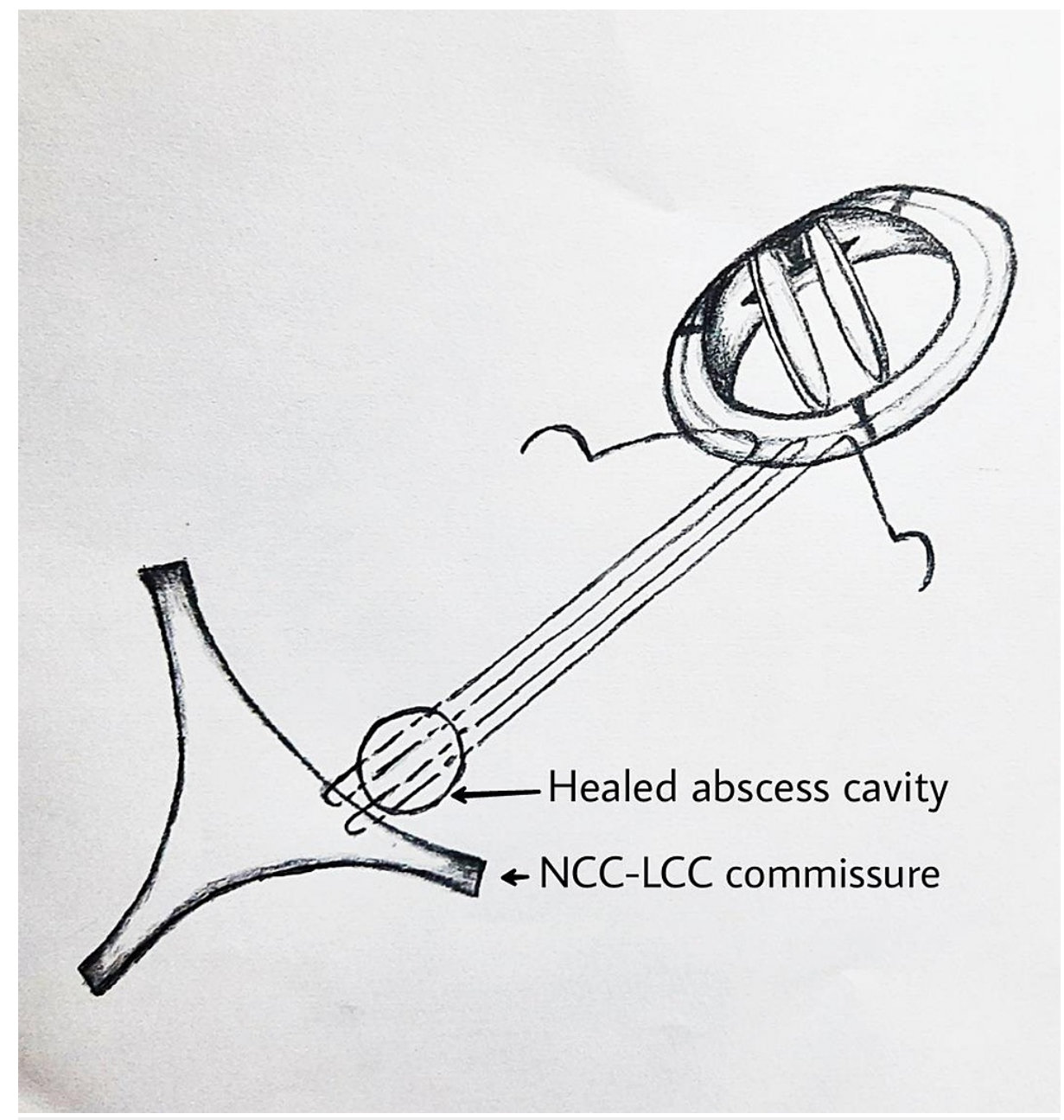

FIGURE 8: Schematic diagram showing placement of valve implantation sutures along with obliteration of abscess cavity.

Posterior segmental suture annuloplasty was done in the mitral valve. The patient was weaned off bypass uneventfully with aortic cross-clamp time being 82 minutes and CPB time being 116 minutes. Post-operative TEE had shown no paravalvular leak (Figures $9 A, 9 B$, and 10A, 10B), normally functioning aortic prosthesis and no MR, which was reconfirmed in the seventh post-operative day TTE (Figures 11A-11D).
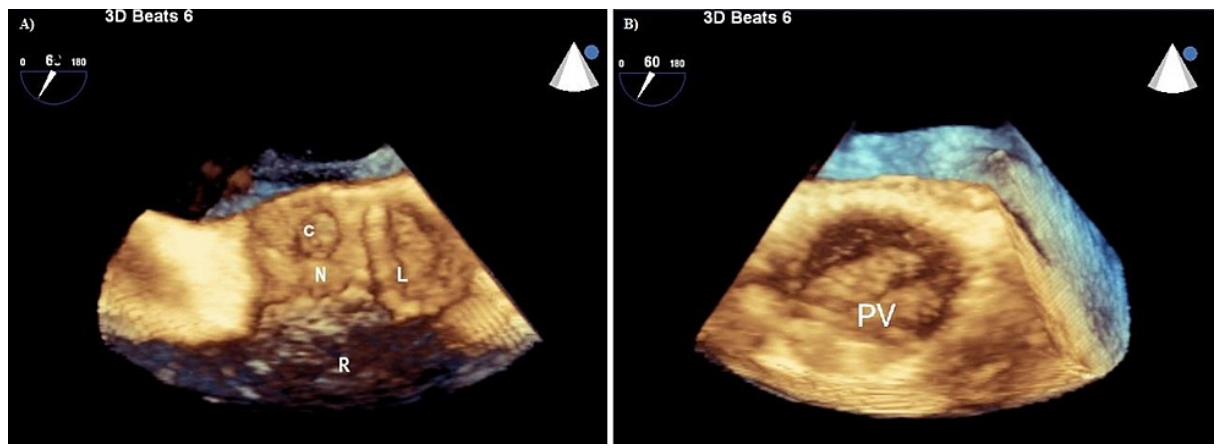

FIGURE 9: 3D zoom crop image obtained by slicing aortic valve deeper

(A) Pre-operative image showing the cavity in proximity to NCC, which goes onto the base of AML. (B) Postoperative image showing obliterated cavity with prosthetic valve implantation.

C - cavity, N - noncoronary cusp, R - right coronary cusp, L - left coronary cusp, PV - prosthetic valve. 


\section{Cureus}

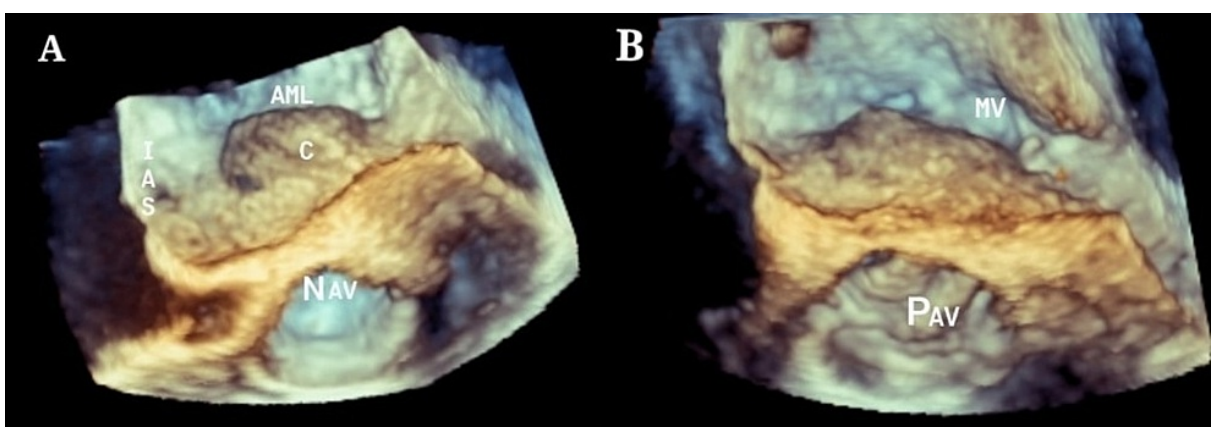

FIGURE 10: 3D zoom image - multi-beta acquisition six ECG beats stitched together

(A) Pre-operative image showing cavity extending into base of AML. (B) Post-operative image showing obliterated cavity post aortic valve implantation.

IAS - inter-atrial septum, AML - anterior mitral leaflet, C - cavity, NAV - native aortic valve, PAV - prosthetic aortic valve, MV - mitral valve.

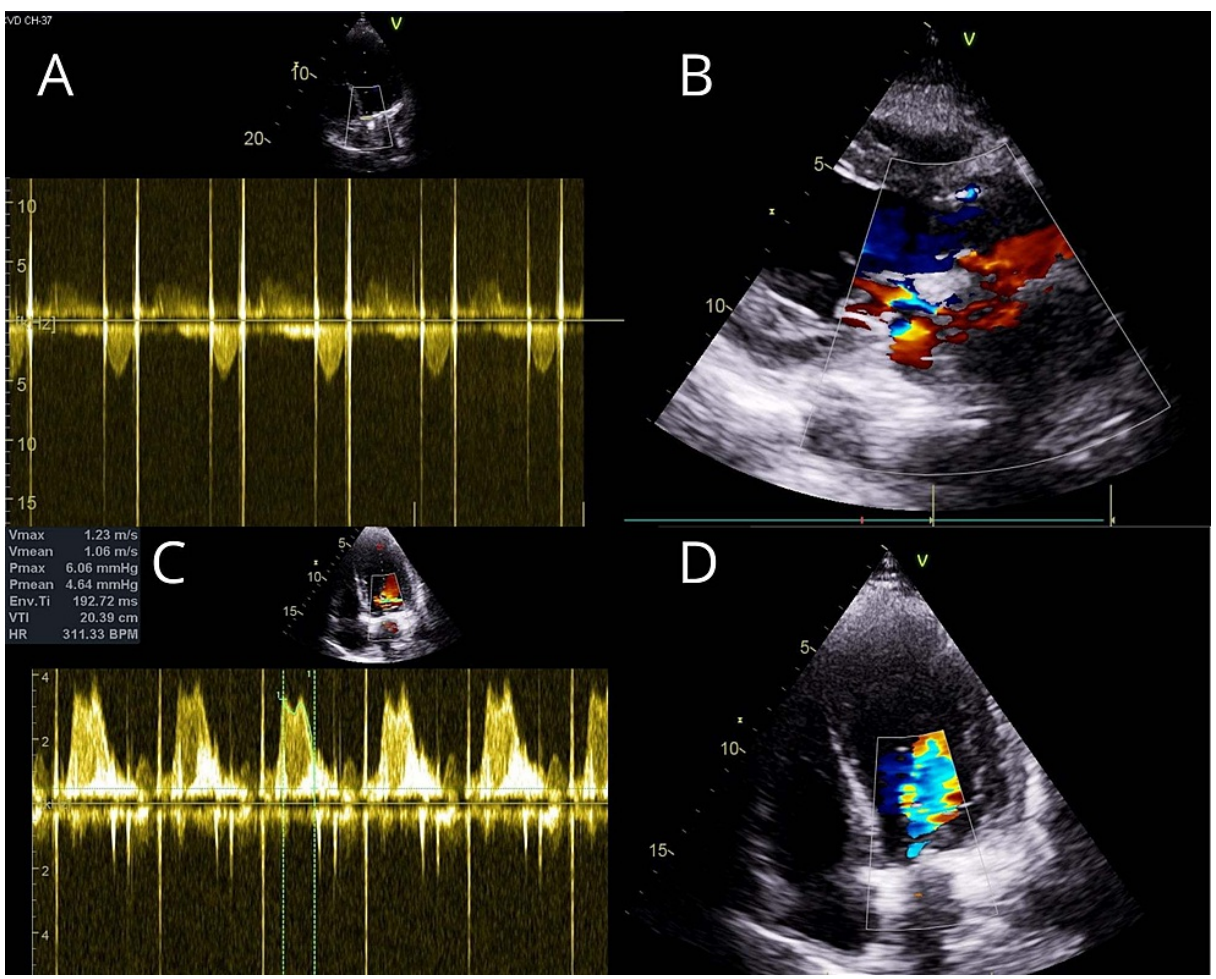

\section{FIGURE 11: Postoperative transthoracic echocardiography}

(A) Five-chamber view with continuous-wave Doppler showing no paravalvular leak. (B) Parasternal long-axis view showing no paravalvular leak. (C) Four-chamber view with continuous-wave Doppler showing no residual mitral regurgitation. (D) Four-chamber view showing no mitral regurgitation.

The patient's course in the hospital was uneventful. The patient was discharged with antiplatelet, anticoagulant (with target international normalized ratio - 2.5-3.5), and eight weeks of antibiotic course prophylactically (as per our infectious disease physician's advice).

\section{Discussion}

A paravalvular abscess usually presents as persistent fever, despite appropriate antibiotic therapy, or as a new conduction abnormality as the abscess erodes into adjacent cardiac conduction tissue. Our patient had none of the above symptoms and there was no other history suggestive of IE and presented with a healed abscess cavity, sequelae of IE. 
The algorithm proposed by the European Society of Cardiology, The Task Force on the Prevention, Diagnosis, and Treatment of IE recommends TEE in patients with high clinical suspicion of IE along with a normal TTE. TEE is always recommended even when the diagnosis is made, as TTE has the better image quality and sensitivity predominantly for perivalvular involvement. With better quality, negative TTE, and low clinical suspicion of IE, only TTE may be considered satisfactory. Intraoperative TEE is recommended in all patients of IE undergoing surgery [5]. We did not do a pre-operative TEE assessment, as the patient presented devoid of any IE features.

As an institutional policy, we electively do TEE for all patients with valvular abnormalities. 3D TEE with the multi beta acquisition is also done, as it gives a more defined quality of images.

The various procedures involved in the repair of aortic abscess included AV replacement with pericardial patch closure of the cavity, annular reconstruction, Bentall's procedure, and other aortic root replacement surgeries.

This case had a healed abscess detected incidentally and a similar case was reported once by Datt et al. where they detected on intraoperative TEE where two healed abscesses were noted. The first was at the NCCLCC commissure and the other on top of the right coronary cusp. The patient had AV (25 mm mechanical valve) and ascending aorta (26 mm Dacron graft) replacement under standard CPB technique [6].

In our patient, the healed abscess cavity was obliterated by including it in the suture line and plicated along with the AV, without using any patching material. It is always good to avoid prosthetic materials, as the chance for reinfection is high. Croon et al., while analyzing the outcome of AV endocarditis with periannular abscess, has found that the mean aortic cross-clamp time was $110 \pm 40$ minutes and mean bypass time of $157 \pm 70$ minutes [7]. Our technique has reduced the aortic cross-clamp and bypass time. The pre-requisite to our technique is that cavity should be nearer to the aortic annulus and should not be too deep. If any suspicion of infection there, then the cavity should be left open.

The left atrial musculature was seen on the floor of our abscess cavity. This shows that on the progression of the abscess it would have developed into a ruptured sinus of valsalva (RSOV) into the left atrium. RSOV rupturing into the left atrium is itself an extremely rare presentation.

\section{Conclusions}

Healed aortic paravalvular abscess is a rare complication of IE. Obliterating the abscess, by simply including it in the suture line while implanting the AV prosthesis is an easier and quicker technique for managing healed periannular abscess. Assessing the characteristics of abscesses with careful selection of surgical techniques is the keystone in the management of these patients.

\section{Additional Information \\ Disclosures}

Human subjects: Consent was obtained or waived by all participants in this study. Conflicts of interest: In compliance with the ICMJE uniform disclosure form, all authors declare the following: Payment/services info: All authors have declared that no financial support was received from any organization for the submitted work. Financial relationships: All authors have declared that they have no financial relationships at present or within the previous three years with any organizations that might have an interest in the submitted work. Other relationships: All authors have declared that there are no other relationships or activities that could appear to have influenced the submitted work.

\section{References}

1. Anguera I, Miro JM, Cabell CH, et al.: Clinical characteristics and outcome of aortic endocarditis with periannular abscess in the International Collaboration on Endocarditis Merged Database. Am J Cardiol. 2005, 96:976-81. 10.1016/j.amjcard.2005.05.056

2. Graupner C, Vilacosta I, SanRomán J, et al.: Periannular extension of infective endocarditis . J Am Coll Cardiol. 2002, 39:1204-11. 10.1016/s0735-1097(02)01747-3

3. Ananthasubramaniam K, Karthikeyan V: Aortic ring abscess and aortoatrial fistula complicating fulminant prosthetic valve endocarditis due to Proteus mirabilis. J Ultrasound Med. 2000, 19:63-6. 10.7863/jum.2000.19.1.63

4. Choussat R, Thomas D, Isnard R, et al.: Perivalvular abscesses associated with endocarditis; clinical features and prognostic factors of overall survival in a series of 233 cases. Perivalvular Abscesses French Multicentre Study. Eur Heart J. 1999, 20:232-41. 10.1053/euhj.1998.1240

5. Habib G, Hoen B, Tornos P, et al.: Guidelines on the prevention, diagnosis, and treatment of infective endocarditis (new version 2009): the Task Force on the Prevention, Diagnosis, and Treatment of Infective Endocarditis of the European Society of Cardiology (ESC). Endorsed by the European Society of Clinical Microbiology and Infectious Diseases (ESCMID) and the International Society of Chemotherapy (ISC) for Infection and Cancer. Eur Heart J. 2009, 30:2369-413. 10.1093/eurheartj/ehp285

6. Datt V, Diwakar A, Malik I, Geelani MA, Tomar AS, Virmani S: Healed perivalvular abscess: incidental 


\section{Cureus}

finding on transesophageal echocardiography [corrected]. Ann Card Anaesth. 2014, 17:141-4. 10.4103/09719784.129862

7. Croon SI, Angkasuwan A, van Straten AH, Khamooshian A, Elenbaas TW, Soliman-Hamad MA: Surgical treatment and long-term outcome of aortic valve endocarditis with periannular abscess. Neth Heart J. 2020, 28:345-53. 10.1007/s12471-020-01409-x 